\title{
NDP-081
}

\section{Interannual Variability in Global Soil Respiration on a 0.5 Degree Grid Cell Basis (1980-1994)}

Contributed by: James W. Raich ${ }^{1}$, Christopher S. Potter ${ }^{2}$, and Dwipen Bhagawati ${ }^{3}$

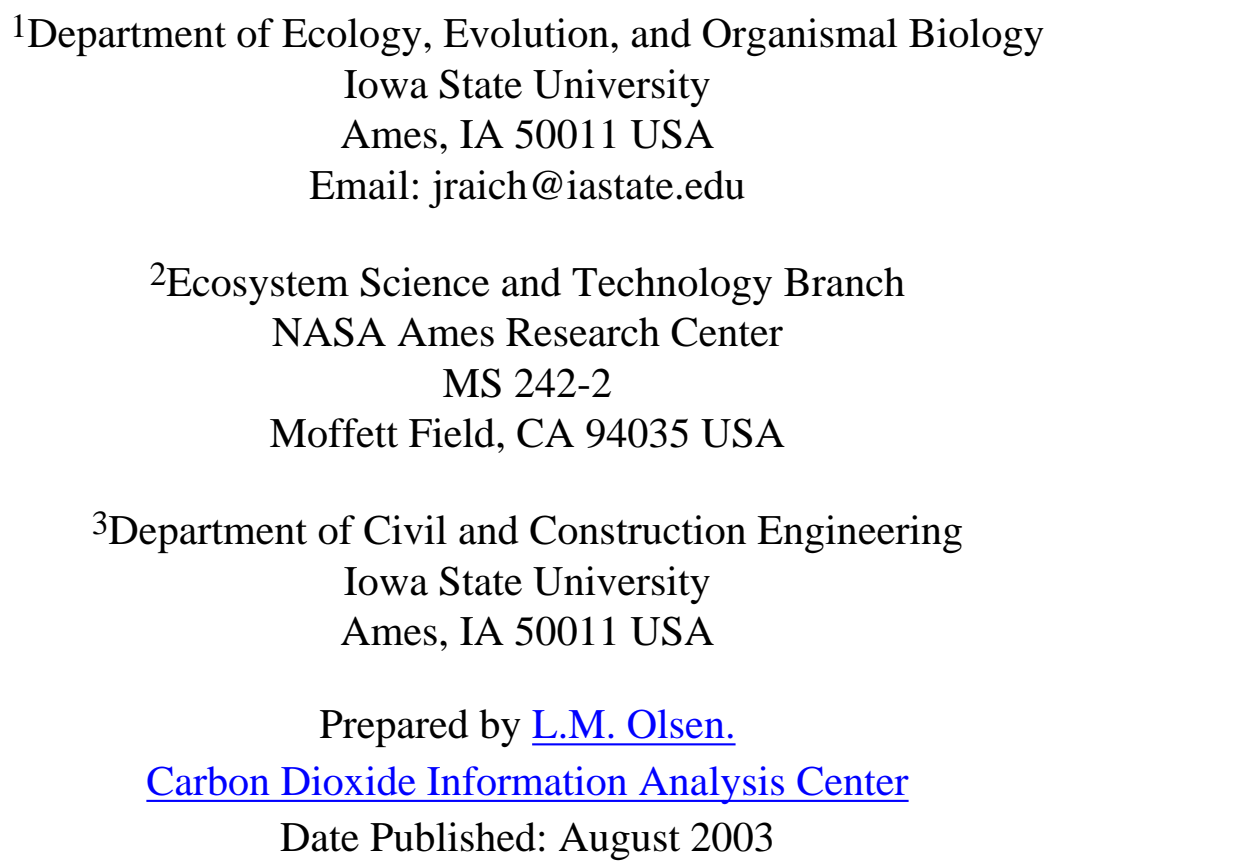

The Carbon Dioxide Information Analysis Center is a part of the Environmental Sciences Division of the OAK RIDGE NATIONAL LABORATORY (ORNL) and is located in Oak Ridge, Tennessee 37831-6335. The ORNL is managed by University of Tennessee-Battelle, LLC for the U.S. DEPARTMENT OF ENERGY under contract DE-AC05-00OR22725

\section{CONTENTS}

$\underline{\text { ABBREVIATIONS }}$

\section{$\underline{\text { ABSTRACT }}$}

\section{BACKGROUND INFORMATION}

\section{DATA CHECKS PERFORMED BY CDIAC}

\section{REFERENCES}

\section{HOW TO OBTAIN THE DATA AND DOCUMENTATION}




\section{LISTING OF FILES PROVIDED}

\section{DESCRIPTION OF THE DOCUMENTATION FILE}

\section{DESCRIPTION, FORMAT, AND PARTIAL LISTINGS OF THE DATA FILES}

\section{ABBREVIATIONS}

$\mathrm{CO}_{2}=$ Carbon Dioxide

CDIAC $=$ Carbon Dioxide Information Analysis Center

FTP = file transfer protocol

$\mathrm{QA}=$ quality assurance

GIS = geographic information system

ARC/INFO is a registered trademark of the Environmental Systems Research Institute, Inc., Redlands, CA 92372.

\section{ABSTRACT}

Raich, J. W., C. S. Potter, and D. Bhagawati. 2002. Interannual variability in global soil respiration, 1980-94. Global Change Biology 8:800-812.

We used a climate-driven regression model to develop spatially resolved estimates of soil- $\mathrm{CO}_{2}$ emissions from the terrestrial land surface for each month from January 1980 to December 1994, to evaluate the effects of interannual variations in climate on global soil-to-atmosphere $\mathrm{CO}_{2}$ fluxes. The mean annual global soil- $\mathrm{CO}_{2}$ flux over this $15-\mathrm{y}$ period was estimated to be 80.4 (range 79.3-81.8) Pg C. Monthly variations in global soil- $\mathrm{CO}_{2}$ emissions followed closely the mean temperature cycle of the Northern Hemisphere. Globally, soil- $\mathrm{CO}_{2}$ emissions reached their minima in February and peaked in July and August. Tropical and subtropical evergreen broad-leaved forests contributed more soil-derived $\mathrm{CO}_{2}$ to the atmosphere than did any other vegetation type ( $\sim 30 \%$ of the total) and exhibited a biannual cycle in their emissions. Soil- $\mathrm{CO}_{2}$ emissions in other biomes exhibited a single annual cycle that paralleled the seasonal temperature cycle. Interannual variability in estimated global soil- $\mathrm{CO}_{2}$ production is substantially less than is variability in net carbon uptake by plants (i.e., net primary productivity). Thus, soils appear to buffer atmospheric $\mathrm{CO}_{2}$ concentrations against far more dramatic seasonal and interannual differences in plant growth. Within seasonally dry biomes (savannas, bushlands, and deserts), interannual variability in soil- $\mathrm{CO}_{2}$ emmissions correlated significantly with interannual differences in precipitation. At the global scale, however, annual soil- $\mathrm{CO}_{2}$ fluxes correlated with mean annual temperature, with a slope of 3.3 $\mathrm{PgCY}^{-1}$ per degree Celsius. Although the distribution of precipitation influences seasonal and spatial patterns of soil- $\mathrm{CO}_{2}$ emissions, global warming is likely to stimulate $\mathrm{CO}_{2}$ emissions from soils.

The user may view and print the body of this publication (Raich, J. W., C. S. Potter, and D. Bhagawati. 2002. Interannual variability in global soil respiration, 1980-94. Global Change Biology 8:800-812) using the free Adobe® Acrobat巴 Reader software. (Reproduced with permission of Blackwell Science Ltd.)

Keywords: Carbon release, climate change, global carbon cycle, global warming, model, soil carbon dioxide emissions. NDP-081 includes the following data and documentation files:

- Descriptive text file (ndp081.txt) 
- Compressed archive of ASCII format of monthly grids (monthly_dat.tar.gz)

- Compressed archive of ARC/INFO export file (.e00) format of monthly grids (monthly_e00.tar.gz)

- Compressed archive of ASCII format of monthly means grids (monthly_means_dat.tar.gz)

- Compressed archive of ARC/INFO export file (.e00) format of monthly means grids (monthly_means_e00.tar.gz)

- Compressed archive of ASCII format of daily grids* (daily_dat.tar.gz)

- Compressed archive of ARC/INFO export file (.e00) format of daily grids* (daily_e00.tar.gz)

- ASCII format of land cover grid (landevr3.dat)

- Text file listing the classes included in the land cover grid (landcvr3.txt)

- ARC/INFO export file (.e00) format of land cover grid (landcvr3.e00)

- ASCII format of land area grid (halfarea.dat)

- ARC/INFO export file (.e00) format of land area grid ( $\underline{\text { halfarea.e00) }}$

*Note: one daily grid exists for each month of record between January 1980 and December 1994.

\section{BACKGROUND INFORMATION}

The authors estimated the seasonal and spatial distribution of global soil- $\mathrm{CO}_{2}$ emissions following the regression based modeling approach of Raich and Potter (1995). This database, therefore, contains global, spatially explicit (0.5-degree grid cells) and temporally explicit model output of soil- $\mathrm{CO}_{2}$ emissions. The calculated emissions include the respiration of both soil organisms and plant roots.

Please note that NDP-081 is an update to DB1015. Specifically, DB1015 used long-term climate data as model input while NDP-081 utilizes new climate and land cover data files. Please refer to Raich et al. 2002 , (provided with permission from Blackwell Science Ltd.) for more information.

\section{DATA CHECKS PERFORMED BY CDIAC}

One of the roles of the Carbon Dioxide Information Analysis Center (CDIAC) is quality assurance (QA) of data. The QA process is an important component of the value-added concept of assuring accurate, usable information for researchers, because data received by CDIAC are rarely in condition for immediate distribution, regardless of source. The following summarizes the QA checks performed on the data files:

1. Calculated the mean annual global soil- $\mathrm{CO}_{2}$ flux over the 15 year period (1980-1994) using the monthly grids. The value (80.4 Pg) was in agreement with the published values of Raich et al. 2002. Note: cells that were assigned a land cover value of 14 (polar ice and rockland) were assigned a value of zero in the monthly and daily data files provided by CDIAC (following the methods used by Raich et al. 2002).

2. Calculated the mean annual global soil- $\mathrm{CO}_{2}$ flux (see above) by land cover type (DeFries et al. 1998). The values were in agreement with those published in Raich et al. 2002.

3. Used the daily data grids to derive monthly data grids by multiplying them by landarea (halfarea.e 00 or halfarea.dat) and number of days per month (methods described by author). When these derived grids were compared with the monthly grids included with this data set, they differed slightly. These differences are probably the result of varying levels of precision in the software used to create them. 
Note: $1 \mathrm{Pg} \mathrm{C}=1 . \mathrm{e} 15 \mathrm{~g} \mathrm{C}$

\section{REFERENCES}

DeFries, R.S, M. Hansen, J.R.G. Townshend, and R. Sohlberg. 1998. Global land cover classifications at 8 km spatial resolution: the use of training data derived from landsat imagery in decision tree classifiers. International Journal of Remote Sensing 19:3141-3168.

Raich, J.W. and C.S. Potter and D. Bhagawati. 2002. Interannual variability in global soil respiration, 1980-1994. Global Change Biology 8:800-812.

Raich, J. W. and C. S. Potter. 1995. Global patterns of carbon dioxide emissions from soils. Global Biogeochemical Cycles 9(1)23-36.

Raich, J.W. and C.S. Potter. 1995. Global patterns of carbon dioxide emissions from soils on a 0.5 degree grid cell basis. DB1015. Carbon Dioxide Information Analysis Center, U.S. Department of Energy, Oak Ridge National Laboratory, Oak Ridge, TN, U.S.A.

\section{HOW TO OBTAIN THE DATA AND DOCUMENTATION}

These data may be used with a raster geographic information system (GIS) or non-GIS database systems. This database (NDP-081) is available free of charge from CDIAC. The files are available, via the Internet, from CDIAC's World-WideWeb site (http://cdiac.ornl.gov), or from CDIAC's anonymous file transfer protocol (FTP) area (cdiac.ornl.gov) as follows:

1. FTP to cdiac.ornl.gov (128.219.24.36).

2. Enter "ftp" as the user id.

3. Enter your electronic mail address as the password (e.g., fred@zulu.org).

4. Change to the directory "pub/ndp081" (i.e., use the command "cd pub/ndp081").

5. Set ftp to get ASCII files by using the ftp "ascii" command.

6. Retrieve the ASCII database documentation file by using the ftp "get ndp081.txt" command.

7. Set ftp to get compressed data files by using the ftp "binary" command.

8. Retrieve the compressed data files by using the ftp "mget *.gzip" command.

9. Exit the system by using the ftp "quit" command.

For non-Internet data acquisitions (e.g., floppy diskette or CD-ROM) or for additional information, contact:

Carbon Dioxide Information Analysis Center

Oak Ridge National Laboratory

P.O. Box 2008

Oak Ridge, Tennessee 37831-6335, U.S.A.

Telephone: 1-865-574-3645

Telefax: 1-865-574-2232

E-mail: cdiac@ornl.gov 


\section{LISTING OF FILES PROVIDED}

This database consists of ten data files (*.dat), and two text files (*.txt).

Data files include:

1. monthly_dat.tar.gz

2. monthly_e00.tar.gz

3. monthly_means_dat.tar.gz

4. monthly_means_e00.tar.gz

5. daily_dat.tar.gz

6. daily_e00.tar.gz

7. halfarea.dat

8. halfarea.e00

9. landcvr3.dat

10. landcvr3.e00

Text files include:

1. ndp081.txt

2. landcvr3.txt

\section{DESCRIPTION OF THE DOCUMENTATION FILES}

The ndp081.txt file is an ASCII text equivalent of this document.

The landcvr3.txt file is a key to the land cover classification codes used in the grid landcvr3.

\section{DESCRIPTION, FORMAT, AND PARTIAL LISTINGS OF THE DATA FILES}

Ten data files are provided with this data package. All grids are global in extent and are unprojected (decimal degrees).

\section{- monthly_dat.tar.gz:}

Grid files of MONTHLY predicted soil $\mathrm{CO}_{2}-\mathrm{C}$ emissions for every month from January 1980 to December 1994. Units are $\mathrm{MgC} /$ gridcell/month. The gzip and tar utilities were used to compress these files in UNIX. This archive contains 180 monthly data files in ASCII format (Please see section below for description). The first two digits in the filename refer to the year and the last two digits refer to the month.

- monthly_e00.tar.gz:

Grid files of MONTHLY predicted soil $\mathrm{CO}_{2}-\mathrm{C}$ emissions for every month from January 1980 to December 1994. Units are $\mathrm{MgC} /$ gridcell/month. The gzip and tar utilities were used to compress these files in UNIX. This archive contains 180 monthly data files in ESRI export format (*e00) (Please see section below for description). The first two digits in the filename refer to the year and the last two digits refer to the month.

- monthly_means_dat.tar.gz:

Grid files containing MONTHLY MEAN soil $\mathrm{CO}_{2}-\mathrm{C}$ emissions as calculated from the monthly data files 
described above (Jan. 1980-Dec. 1994). Units are MgC/gridcell/month. The gzip and tar utilities were used to compress these files in UNIX. This archive contains 12 data files in ASCII format (Please see section below for description). The last two digits in the filename refer to the month.

\section{- monthly_means_e00.tar.gz:}

Grid files containing MONTHLY MEAN soil $\mathrm{CO}_{2}-\mathrm{C}$ emissions as calculated from the monthly data files described above (Jan. 1980-Dec. 1994). Units are MgC/gridcell/month. The gzip and tar utilities were used to compress these files in UNIX. This archive contains 12 data files in ESRI export format (*e0) (Please see section below for description). The last two digits in the filename refer to the month.

\section{- daily_dat.tar.gz:}

Grid files containing predicted DAILY soil $\mathrm{CO}_{2}-\mathrm{C}$ emissions representing every month from January 1980 through December 1994 (one daily file per month). Units are $\mathrm{gC} / \mathrm{m}^{2} /$ day. The gzip and tar utilities were used to compress these files in UNIX. This archive contains 180 data files in ASCII format (Please see section below for description). The first two digits in the filename refer to the year and the last two digits refer to the month.

\section{- daily_e00.tar.gz:}

Grid files containing predicted DAILY soil $\mathrm{CO}_{2}-\mathrm{C}$ emissions representing every month from January 1980 through December 1994 (one daily file per month). Units are $\mathrm{gC} / \mathrm{m}^{2} /$ day. The gzip and tar utilities were used to compress these files in UNIX. This archive contains 180 data files in ESRI export format $\left({ }^{*} \mathrm{e} 00\right)$ (Please see section below for description). The first two digits in the filename refer to the year and the last two digits refer to the month.

\section{- halfarea.dat:}

A 0.5 degree lat/lon file with grid cell area information. Units are $\mathrm{km}^{2} /$ grid cell. This file was used by the authors in the global summation of soil emissions. This file is in ASCII format (Please see section below for description).

\section{- halfarea.e00:}

A 0.5 degree lat/lon file with grid cell area information. Units are $\mathrm{km}^{2} /$ grid cell. This file was used by the authors in the global summation of soil emissions. The file is in ESRI export format $(* \mathrm{e} 00)$ (Please see section below for description).

\section{- landcvr3.dat:}

A 0.5 degree land cover classification based on Defries et al. (1998). This file was used by the authors in the global summation of soil emissions by land cover type. The file is in ASCII format (Please see section below for description).

\section{- landcvr3.e00:}

A 0.5 degree land cover classification based on Defries et al. (1998). This file was used by the authors in the global summation of soil emissions by land cover type. The file is in ESRI export format (*e00). (Please see section below for description)

\section{File formats:}

\section{ASCII GRID:}


Each file contains a single ASCII array with integer values. Coordinates listed below are in decimal degrees.

The ASCII file consists of header information containing a set of keywords, followed by cell values in row-major order. The file format is:

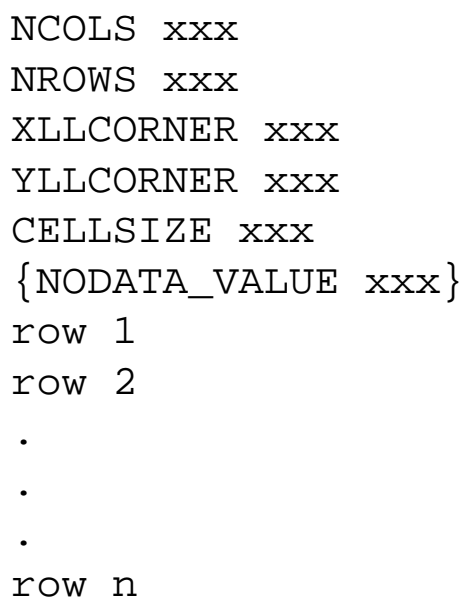

where $\mathrm{xxx}$ is a number, and the keyword NODATA_VALUE is optional and defaults to -9999 . Row 1 of the data is at the top of the grid, row 2 is just under row 1 and so on. The end of each row of data from the grid is terminated with a carriage return in the file.

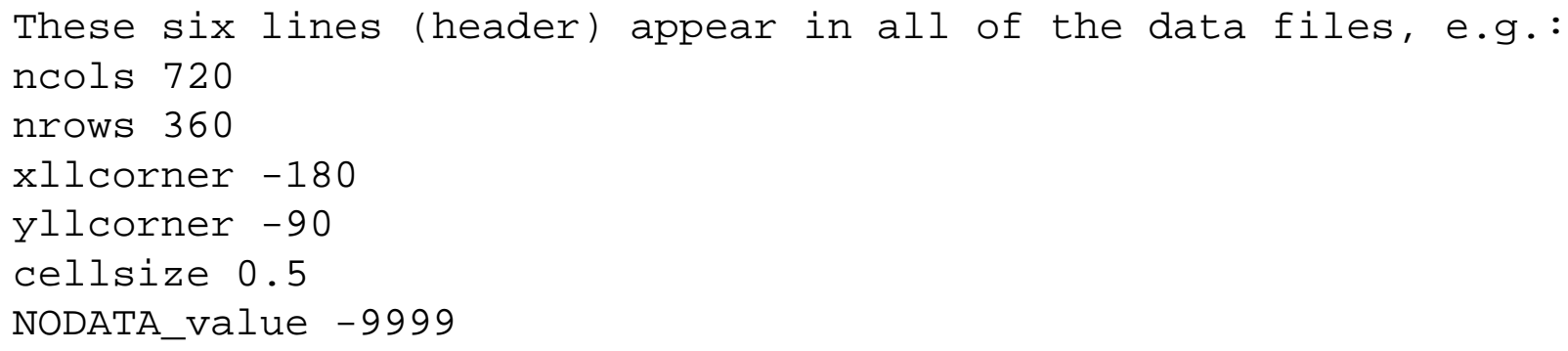

To import this file into ArcInfo use the following command at an ARC prompt:

ASCIIGRID (in_ascii_file) (out_grid) \{INT | FLOAT

Arguments

(in_ascii_file) - the ASCII file to be converted. (out_grid) - the name of the grid to be created. \{INT $\mid$ FLOAT - the data type of the output grid.

INT - an integer grid will be created.

FLOAT - a floating-point grid will be created.

Note: This data can also be imported into ArcView (with Spatial Analyst) and ArcGis as ASCII Raster data.

\section{ARC/INFO EXPORT FILES:}


ESRI EXPORT file (*.e00) - is a proprietary format that can be imported into ARC/INFO GRID using the following command at an ARC prompt:

IMPORT (option) (interchange_file) (output)

Arguments

(option) - GRID

(interchange_file) - the name of the *e00 file to be converted

(output) - a user specified output file

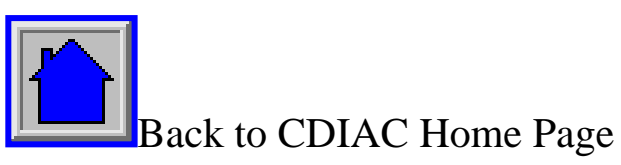

